\title{
Numerical Studies of Penetration in Light Armor, Concrete and Brick-Wall Targets
}

\author{
Sheikh Muhammad Zakir ${ }^{1}$, Suo Tao ${ }^{1}$, Li Yulong ${ }^{1}$ \\ Ahmed Sohail $^{1}$, Dar Uzair Ahmed ${ }^{1}$, Rasheed Muhammad Farrukh ${ }^{2}$
}

\author{
${ }^{1}$ School of Aeronautics, Northwestern Polytechnical University, Xi'an,710072, People's Republic of China, Shaanxi, \\ Xian, China. \\ ${ }^{2}$ Department of Mechatronics, Beijing Institute of Technology, People's Republic of China, Beijing, Beijing, \\ China. \\ e-mail: sheikhzakir@mail.nwpu.edu.cn, suotao@nwpu.edu.cn, liyulong@nwpu.edu.cn, s.ahmed@mail.nwpu.edu.cn, \\ uzair@mail.nwpu.edu.cn, farrukh@bit.edu.cn
}

\begin{abstract}
The accurate numerical simulation of projectile penetration process is a complex challenge. Experimental investigation of these time-dependent non-linear events is expensive and time-consuming. In this paper, 3-D numerical simulations are carried out to estimate the penetration performance of designed penetrators against the double and triple brick-wall, plain concrete wall and light armor targets at impact velocities of 120 to 300 $\mathrm{m} / \mathrm{s}$, undergoing normal and oblique impacts. In all simulations, both the projectile and targets are modeled using Lagrange solver facility, available in ANSYS/Autodyn. During penetration process, targets experience severe grid deformation in the region local to the penetrator. Highly distorted elements are removed from the calculation using erosion strain algorithm. The simulation results suggest that at maximum velocity flat-nose (FN) projectile successfully perforate all the targets with significant residual velocity, for both normal and maximum oblique impact scenarios. For impact velocity of $120 \mathrm{~m} / \mathrm{s}$, the FN projectile perforated the armor and concrete targets but was not able to penetrate and cross through these targets. However, both brick-wall targets were perforated at normal and maximum oblique angle with sufficient residual velocity. The validation of the calculated results and numerical setup were made with experiments against double and triple brick-wall targets for impacting velocity of $170 \mathrm{~m} / \mathrm{s}$. Good agreement between the experimental and estimated projectile residual velocity has been achieved. In contrast to FN projectile, the ogive-nose penetrator calculated results has shown ricocheting behavior on impacting the light armor target at minimum velocity and maximum obliquity. The FN projectile has shown better perforation and penetration performance against light armor and domestic targets. The projectile minimum velocity is also estimated numerically to fully penetrate three different types of targets. These results would be beneficial for the designers and operators to get the desired performance against domestic and light armor targets with sureness.
\end{abstract}

Keywords: Numerical simulation, Oblique impact, Perforation, Penetration, Brick-wall

\section{INTRODUCTION}

The increased urban combat requires the designers and battlefield planners to have accurate information regarding the effects of their existing and new weapons against the variety of targets like light armor vehicles and walls made of concrete, brick, adobe, and masonry. The advancement in numerical techniques makes it easier for a designer to simulate the dynamic problems of impact, penetration, and explosions to a variety of targets. Researchers are using these sophisticated codes [1-7] from many decades to simulate the blast and penetration phenomenon for metallic, concrete and masonry materials to capture the detailed failure damage mechanism experienced by both projectile and targets. Akers, et.al., [8] have studied numerically the breaching hole and crater size of triple-brick walls using coupled Elurian-Lagrange code Zepotec and good agreement was found with experiments. The ogive-nose steel projectile ballistic limit studies on reinforced concrete structures using RHT (Riedel Hiermaier Thoma) strength model at 300 and $1000 \mathrm{~m} / \mathrm{s}$ for normal impact 
were analyzed [9] and found a good correlation with experiments in terms of damage and perforation velocities. The author also concluded that near the ballistic limit, concrete strain rate and pressure dependent failure phenomenon becomes more important and projectile perforation, well above the ballistic limit, is insensitive to concrete strength model. Zakir, et.al., [10] studied the ogive-nose projectile impact on reinforced concrete structures using dynamic finite element software ANSYS/Autodyn and found the projectile residual velocity for different reinforcing bar arrangements and ricocheting angle for various impacting velocities. Grujicic, et.al., [11] numerically investigated the dynamic load and residual projectile velocity results against the impact on different structures including hard, soft and urban targets, to guide the design and development of a three different mode smart-fuze for target discrimination. The penetration of a unitary penetrator against mild steel, double reinforced concrete, and double brick-wall targets was studied by Lips, et.al., [12]. Simulations were completed using Autodyn and good agreement was found with field tests. Most recently [13] explored the effect of boundary condition, bonding pattern, and a wall thickness of masonry walls to vented gas explosions. Their study aftermath suggested that only wall thickness and boundary conditions influence the brick-walls performance to vented explosions

In the present work, the design and development of a penetrator for defeating the multiple targets particularly concrete, double and triple brick-wall and light weight armor are deliberated. The commercially available nonlinear finite element (FE) based software ANSYS/Autodyn is used for design verification and penetration capability of deigned penetrators at normal and maximum obliquity of $30^{\circ}$. The ogive-nose projectile has shown the ricocheting behavior as suggested by the ogive-nose projectile simulations on light armor targets at a minimum velocity of $120 \mathrm{~m} / \mathrm{s}$ and maximum obliquity. Therefore, further work in this paper is accomplished using second designed flat-nose (FN) projectile impact on various targets of concern. The numerical result suggested that at maximum velocity and obliquity, the FN projectile penetrated all the targets with sufficient residual velocity. At the minimum velocity and maximum obliquity, the FN projectile can perforate the normal strength concrete and half inches thick rolled homogeneous armor targets but was not able to penetrate and cross through these targets with adequate residual velocity. However, at minimum velocity and normal and $30^{\circ}$ impact angles, both the double and triple brick wall targets were perforated with adequate residual velocity. Experimental tests against brick walls verified the penetrator performance. The simulations and test results would be beneficial for the designers and operators to design an efficient initiating system to get the desired performance against domestic and light armor targets.

\section{COMPUTATIONAL SCHEME}

\subsection{Dynamic modeling of projectile and target}

In present work, as mentioned earlier, the designed projectiles (flat and ogive-nose) impacted the three different targets (light armor, concrete, and domestic brick-wall buildings) and these transient non-linear simulations are conducted using general purpose software ANSYS/Autodyn. The projectile residual velocity and penetration capability in these targets at different velocities for normal and oblique impact are analyzed. In all the simulations the projectile and target are discretized as 3-D solid elements with Lagrange formulation and Lagrange/Lagrange interaction logic with erosion models are employed. The suitable mass, momentum, and energy conservation equations with the appropriate initial and boundary conditions and transient nonlinear materials models available in ANSYS/Autodyn are considered for analysis. The material with strength, damage, erosion models with the corresponding equation of state (EOS) are discussed in next section.

\subsection{Materials and models}

In this section, three different targets (RHA, concrete, and brick-wall) and projectile numerical modeling are discussed for dynamic penetration analysis.

\subsubsection{Projectile}

The flat and ogive nose projectiles of mass $5.5 \mathrm{~kg}$ and nominal diameter of $94 \mathrm{~mm}$ with the length of $220 \mathrm{~mm}$ are modeled with Lagrange formulation employing 3-D solid elements. However, ogive nose projectile on impacting the RHA target at a lower velocity and maximum obliquity showed the tendency to ricochet (see section 3, figure 4). Therefore, the flat-nose penetrator is used in rest of the simulations and experimentation.

The finite element (FE) model of the flat-nose projectile with inert filling is shown in figure 1 . The projectile is modeled as Steel 4340 material with shock EOS and Johnson-cook (JC) strength model. The JC (1983) constitutive material model describes the flow stress $(\sigma)$ of metal as a function of plastic strain $\left(\varepsilon_{p l}\right)$, plastic strain rate $\left(\varepsilon_{p l}^{\cdot}\right)$, and temperature $(T)$ as: 


$$
\sigma=\left(A+B \varepsilon_{p l}^{n}\right)\left(1+C \ln \frac{\varepsilon_{p l}^{\bullet}}{\varepsilon_{p l, 0}^{\bullet}}\right)\left(1-\left(\frac{T-T_{R o o m}}{T_{\text {melt }}-T_{\text {Room }}}\right)^{m}\right)
$$

Where $A$ is the yield stress at zero plastic strain, $B$ is hardening constant, $\mathrm{n}$ is hardening exponent, $\mathrm{C}$ is strain rate constant, $\mathrm{m}$ is thermal softening constant, the reference value for plastic strain rate, and are material constants, $T_{\text {melt }}$ is the melt temperature of the material, $T_{\text {room }}$ is the ambient temperature. The projectile material parameters of steel 4340 employed in simulations [14] are listed in table-1.

Table 1: Johnson and Cook strength model parameters for steel 4340 [15]

\begin{tabular}{lclc}
\hline Parameter & Value & Parameter & Value \\
\hline Density $\left(\mathrm{Kg} / \mathrm{m}^{3}\right)$ & 7830 & Hardening exponent, $\mathrm{n}(--)$ & 0.26 \\
\hline Specific heat, $\boldsymbol{C}_{\boldsymbol{v}}(\mathrm{J} / \mathrm{Kg} \mathrm{K})$ & 477 & Strain-rate constant, c (--) & 0.014 \\
\hline Melt temperature, $\boldsymbol{T}_{\text {melt }}(\mathrm{K})$ & 1793 & Thermal softening constant, $\mathrm{m}(--)$ & 1.03 \\
\hline Yield stress, A $(\mathrm{MPa})$ & 792 & Modulus of Elasticity, E $(\mathrm{MPa})$ & 207 \\
\hline Hardening constant, B $(\mathrm{MPa})$ & 510 & Poisson ratio, $\mathrm{v}(--)$ & 0.29 \\
\hline
\end{tabular}

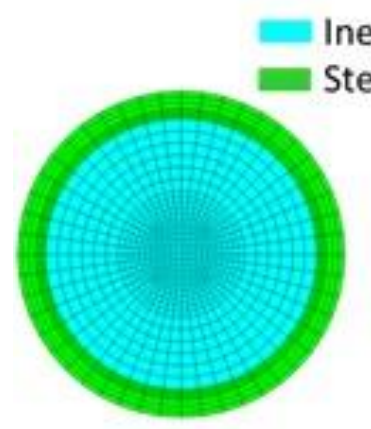

Back view
Inert Filling

Steel 4340

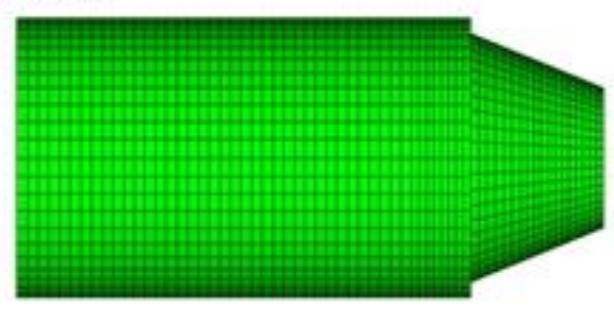

Side view

Figure 1: FE model of the flat-nose projectile

\subsubsection{RHA}

The light armor vehicles and vessels are generally protected by hard steel (RHA) and their thicknesses vary from 6.35 to 12.7 millimeters. In simulations, for simplicity, these targets are modeled as RHA plate of size, $500 \times 500 \times 12.7 \mathrm{~mm}$ and the refined mesh is made in impact region, as shown in figure 2 . The quarter and half symmetry are assumed for normal and oblique impact scenarios respectively. The target material model consists of shock EOS, Von-Mises strength, and incremental geometric strain erosion model. The MieGruneisen form of EOS based on shock Hugonoit is as follows:

$$
p=p_{H}+\Gamma \rho\left(e-e_{H}\right)
$$

Where $p$ is pressure, $e$ is specific energy $\Gamma$ is the Gruneisen Gamma coefficient and is equal to $B_{o} /(1+\mu)$ where $B_{O}$ is a constant, and $\rho$ is the density. $p_{H}$ and $e_{H}$ are the Hugoniot pressure and energy, respectively, given by;

$$
\begin{aligned}
& p_{H}=p_{H}+\rho_{O} C_{1}^{2} \mu(1+\mu) /\left[1-\left(S_{1}-1\right) \mu\right]^{2} \\
& e_{H}=1 / 2 \cdot p_{H} / \rho_{O} \cdot(\mu / 1+\mu)
\end{aligned}
$$

Where $\mu=\rho / \rho_{O}-1$ is compressibility, $C_{1}$ is bulk speed sound and $S_{1}$ is Hugoniot linear slope coefficient. The parameters $C_{1}$ and $S_{1}$ define the linear relationship between shock velocity, $U_{S}$ and the particle velocity $U_{P}$, as follows: 


$$
U_{S}=C_{1}+S_{1} U_{P}
$$

The input data of target material to hydrocode ANSYS/Autodyn is listed in table- 2 .

Table 2: The EOS and strength parameters for RHA

\begin{tabular}{cccccccc}
\hline \multicolumn{4}{c}{ EOS Parameters } & \multicolumn{3}{c}{ Strength parameters } \\
$\begin{array}{c}\text { Reference } \\
\text { density, } \boldsymbol{\rho}_{\mathbf{0}} \\
\left(\mathbf{k g} / \mathbf{m}^{3}\right)\end{array}$ & $\begin{array}{c}\text { Gruneisen } \\
\text { Coefficient, } \boldsymbol{\Gamma}\end{array}$ & $\begin{array}{c}\text { Sound } \\
\mathbf{s p e e d ,} \mathbf{C}_{1} \\
(\mathbf{m} / \mathbf{s})\end{array}$ & $\begin{array}{c}\text { Parametre } \\
\mathbf{S}_{1}\end{array}$ & $\begin{array}{c}\text { Shear } \\
\text { modulus, G }\end{array}$ & $\begin{array}{c}\text { Yield } \\
\text { strength, } \boldsymbol{\sigma}_{Y}\end{array}$ & $\begin{array}{c}\text { Erosion } \\
\text { strain } \\
(\mathbf{K P a})\end{array}$ & $\begin{array}{c}(\mathrm{KPa}) \\
(-)\end{array}$ \\
\hline 7850 & 1.67 & $4.61 \mathrm{e} 3$ & 1.73 & $7.7 \mathrm{e} 6$ & $1.5 \mathrm{e} 6$ & 1.5 \\
\hline
\end{tabular}

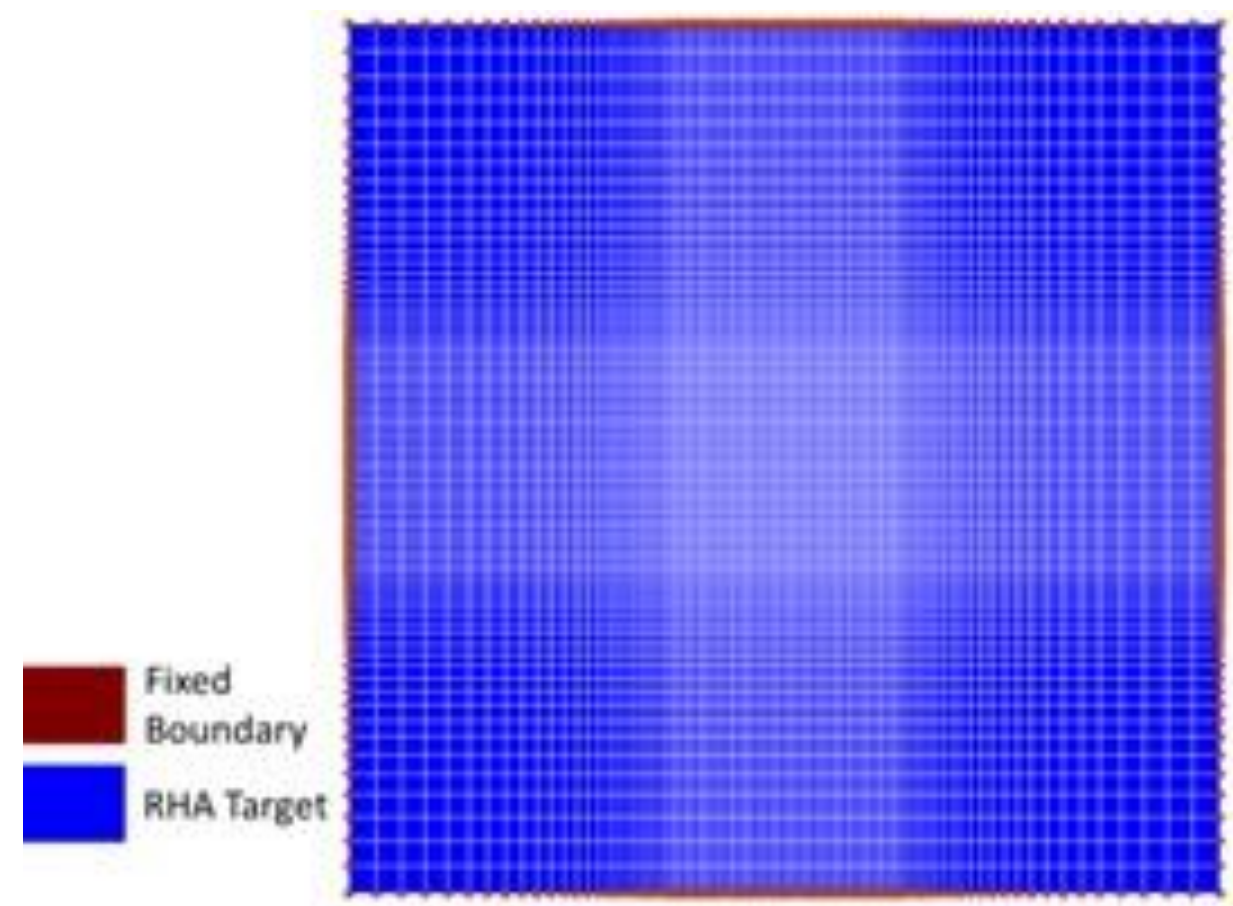

Figure 2: Finite Element (FE) model of RHA target

\subsubsection{Plain concrete target}

The plain/unitary concrete target wall of 8 inches thickness is modeled as solid elements formulation in simulations for normal and inclined impact to incoming projectiles. The square wall of size 1.5 meter is numerically discretized with a quarter and the half plane of symmetry correspondingly. The concrete target impact region is meshed with an element size of $5 \mathrm{~mm}$ and the coarse mesh is used in a region away from the impact area. The plain concrete wall of compressive strength $35 \mathrm{MPa}$ with RHT model is computationally analyzed for normal and oblique impact condition at impact velocities of 300 and $120 \mathrm{~m} / \mathrm{s}$. The RHT concrete model is developed at Ernst-Mach-Institute and since 2000 this model is readily available to all users of commercially available hydrocode ANSYS/Autodyn. This model has tri-axial stress state and also takes into account pressure hardening, strain hardening and strain-rate hardening as well as the third invariance in the deviatoric plane. The background of RHT concrete model, development and successful use of various blast and impact simulations worldwide was studied by Riedel [16]. The concrete target was modeled with (P- $\alpha)$ EOS which correlates pressure as a function of material compaction, this was introduced by Herrmann [17]. The porosity $(\alpha)$ is given by;

$$
\alpha=V_{\text {porous }} / V_{\text {Solid }}=\rho_{\text {solid }} / \rho_{\text {porous }}
$$

Where, $V_{\text {porous }}$ and $V_{\text {solid }}$ are the specific densities of the porous and solid-state material, respectively at the same temperature and pressure conditions. The generalized form of $(\mathrm{P}-\alpha)$ EOS is given by: 


$$
p=1 / \alpha f(\alpha \cdot \rho, e)
$$

The (P- $\alpha)$ EOS when combines with polynomial EOS, takes the form as of equation (8), with present porosity, $\alpha$, which depend on the porosity of undamaged concrete $(\alpha$ porous $)$, the hydrostatic pressure $(p)$, and a compaction exponenet $(n)$, as given in equation (9).

$$
\begin{aligned}
& f(\rho, e)=A 1 \mu+A 2 \mu^{2}+A 3 \mu^{3}+\left(B_{o}+B 1 \mu\right) \rho_{o} e \text { where } \mu=\rho / \rho_{o}-1 \\
& \alpha=1+\left(\alpha_{\text {porous }} 1\right)\left[p_{s}-p / p_{s}-p_{e}\right]^{n}
\end{aligned}
$$

Where $p_{s}$ and $p_{e}$ are solid compaction pressure and initial compaction pressure parameters, respectively.The factors $A 1, A 2, A 3, B_{0}$ and, $B 1$, are material parameters describing the shape of the EOS curve and $e$ is the internal energy. The RHT concrete with $(\mathrm{P}-\alpha)$ EOS and strength parameters used in simulations are given

\begin{tabular}{|c|c|c|c|}
\hline Parameter & Value & Parameter & Value \\
\hline Initial Density, $\rho_{0}\left(\mathrm{~kg} / \mathrm{m}^{3}\right)$ & 2390 & Bulk modulus A1 (GPa) & 40 \\
\hline Porous Density, $\rho_{\text {porous }}\left(\mathrm{Kg} / \mathrm{m}^{3}\right)$ & 2390 & Parametre, $A 2$ (GPa) & 0 \\
\hline Initial Compaction Pressure, $p_{e}(\mathrm{MPa})$ & 80 & Parametre, $\mathrm{B}_{0}(--)$ & 1.22 \\
\hline Solid Compaction Pressure, $\boldsymbol{p}_{\boldsymbol{s}}$ (MPa) & 1800 & Parametre, B1 (--) & 1.22 \\
\hline Compaction Exponent, $n$ & 5 & Parametre, T1 (GPa) & 40 \\
\hline$\rho_{\text {solid }}\left(\mathrm{Kg} / \mathrm{m}^{3}\right)$ & 2540 & Reference tepmrature, $\mathrm{T}_{\text {ref }}(\mathrm{K})$ & 300 \\
\hline
\end{tabular}
in table 3 and 4.

Table 3: RHT concrete model EOS input data

Table 4: RHT strength model parameters for $35 \mathrm{MPa}$ concrete

\begin{tabular}{cccc}
\hline Parameter & Value & Parameter & Value \\
\hline Shear Modulus, $\boldsymbol{G}(\mathrm{GPa})$ & 16.7 & Residual strength constant, $\mathrm{B}$ & 1.6 \\
\hline Compressive Strength, $\boldsymbol{f}_{\boldsymbol{c}}(\mathrm{MPa})$ & 35.0 & Residual strength exponent, $\boldsymbol{M}$ & 0.61 \\
\hline Tensile compressive strength ratio & 0.10 & Compressive strain rate exponent, $\boldsymbol{\alpha}$ & 0.10 \\
\hline Shear compressive strength ratio & 0.18 & Tensile strain rate exponent, $\boldsymbol{\delta}$ & 0.013 \\
\hline Failure surface parameter, $\boldsymbol{A}$ & 1.9 & Damage constant, $\boldsymbol{D} 1$ & 0.04 \\
\hline Failure surface exponent, $\boldsymbol{N}$ & 0.6 & Damage exponent, $\boldsymbol{D 2}$ & 1.0 \\
\hline Tensile compression meridian ratio, $\mathbf{Q 2}$ & 0.6805 & Minimum strain to failure , $\boldsymbol{E}_{\boldsymbol{f}, \boldsymbol{m i n}}$ & 0.01 \\
\hline
\end{tabular}

\subsubsection{Brick-wall targets}

Double and triple-brick wall targets of thickness 9 and 13 inches respectively are analyzed in this paper to represent the generalized domestic/urban buildings. The overall dimensions of the walls are 4.10 meter in width and 2.73 meters in height. The half symmetry is applied and modeled width of brick-wall is 2.05 meter with 9 layers of bricks in each row. The nominal dimensions of the commercially available bricks of size $9 \mathrm{x}$ $4.5 \times 3$ inches are used to construct the wall. The mortar joint thickness of $10 \mathrm{~mm}$ is assumed and both the $(9$ 
and 13 inches) brick-wall targets are established numerically using 3D-Frag/Brick geometric technique available in Ansys/Autodyn. The typical laying configuration of the triple brick-wall structure is shown in figure 3.

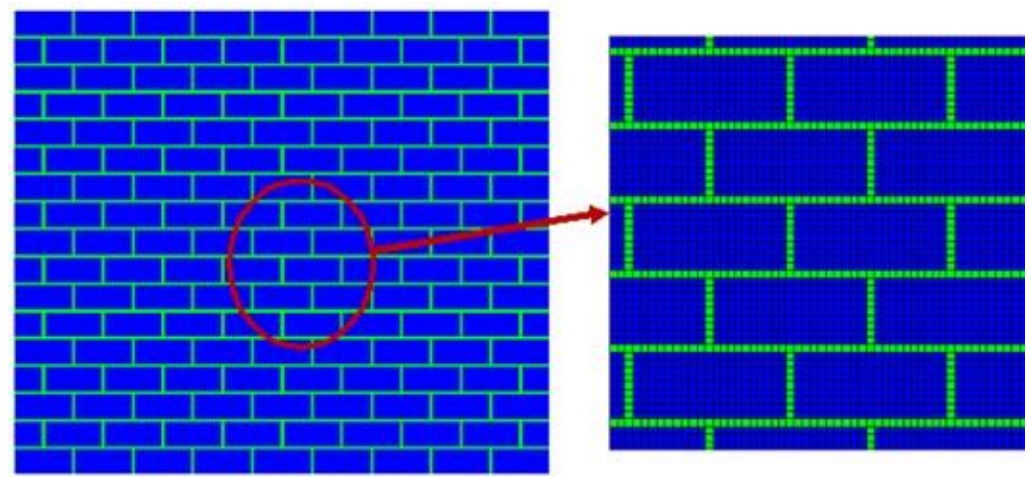

Figure 3: FE model of 13 Inches thick triple brick-wall target

In this work, double and triple layer masonry brick wall targets are heterogeneously modeled to estimate the accurate projectile residual velocity after perforation. However, most of the published work available on masonry walls is relevant to its performance to blast effects. Brick-walls are composite structures, consist of bricks and adjoining mortar. The variation in material properties of brick and mortar and their complex interaction makes it difficult to understand the masonry behavior to impact and blast loading. A less open ligature is available for modeling, simulation, and analysis of brick-walls (brick and mortar) subjected to projectile impact. A discrete, heterogeneous constitutive material model of brick and mortar are also not available in hydrocodes. The dynamic material model and properties of concrete are well established and these constitutive models are used in $[18,19]$ to discretize homogenized numerical representation of brick and mortar masonry walls. These homogenized models are computationally cost effective but cannot predict accurately the fragments size and ejected velocity. Wei, et.al., [20] studied numerically the blast response of unreinforced masonry brick-wall using strain-rate material models for both brick and mortar with good agreement with experiments. In recent past, [21] successfully attempted to develop the strength, damage and pressure behavior of brick and mortar for Holmquist-Johnson-Cook (HJC) model. Zhou, et.al., [7] proposed a dynamic continuum damage material model for both brick and mortar with their respective material properties and successfully implemented it in ASYS/Autodyn through user-subroutine. In [22], the authors studied experimentally the dynamic material properties of brick and mortar in detail, and presented a dynamic increase factor (DIF ratio of dynamic to static strength) parameter as a function of strain rate $\left(\varepsilon^{*}\right)$, yield strength and strain, ultimate strength and strain; brick Poisson's ratio and elastic modulus of both brick and mortar materials. The derived DIF [23] equations for both the brick and mortar are given below:

Brick strength,

$$
\begin{aligned}
& D I F=0.0268 \ln \varepsilon^{\bullet}+1.33504 \text { for } \varepsilon^{\bullet} \leq 3.2 s^{-1} \\
& D I F=0.2405 \ln \varepsilon^{\bullet}+1.1041 \text { for } \varepsilon^{\bullet}>3.2 s^{-1}
\end{aligned}
$$

Mortar strength,

$$
\begin{array}{ll}
D I F=0.0372 \ln \varepsilon^{\bullet}+1.4025 & \text { for } \varepsilon^{\bullet} \leq 13 s^{-1} \\
D I F=0.3447 \ln \varepsilon^{\bullet}+0.5987 & \text { for } \varepsilon^{\bullet}>13 s^{-1}
\end{array}
$$

Young's modulus of brick,

$$
\begin{array}{ll}
D I F=0.0013 \ln \varepsilon^{\bullet}+1.0174 & \text { for } \varepsilon^{\bullet} \leq 7.3 s^{-1} \\
D I F=0.3079 \ln \varepsilon^{\bullet}+0.4063 & \text { for } \varepsilon^{\bullet}>13 s^{-1}
\end{array}
$$

The ultimate strain of brick and mortar respectively, 


$$
\begin{aligned}
& D I F=0.00067 \ln \varepsilon^{\bullet}+1.0876 \\
& D I F=0.1523 \ln \varepsilon^{\bullet}+2.6479
\end{aligned}
$$

Poisson's ratio for both brick and mortar materials are taken as constant.

In present work, this material model having Drucker-Prager strength, linear EOS and cumulative damage are used to numerically discretize the double and triple brick-wall targets to normal and oblique impacts. The details of strength model, damage and EOS can be found in reference [23]. The material properties used in simulations for brick and mortar are taken from [7] and listed in table-5.

\begin{tabular}{|c|c|c|}
\hline Material Parameters & Brick & Mortar \\
\hline Density $\left(\mathrm{Kg} / \mathrm{m}^{3}\right)$ & 1986 & 1604 \\
\hline Elastic modulus, (GPa) & 10 & 2 \\
\hline Shear modulus, (GPa) & 4.46 & 0.83 \\
\hline Poisson's ratio & 0.12 & 0.2 \\
\hline Uniaxial tensile strength (MPa) & 4 & 0.56 \\
\hline Uniaxial compressive strength (MPa) & 40 & 5.6 \\
\hline uniaxial compressive strain, $\varepsilon_{c o}$ & 0.00025 & 0.0025 \\
\hline
\end{tabular}

Table 5: Material parameters for brick and mortar

\section{RESULTS AND DISCUSSION}

In this paper, an attempt is made to analyze the penetration performance of projectile to three different targets namely light armor, concrete and brick-walls. Numerical results are discussed here and comparison of calculated and experimental results is made for the normal impact of brick-wall targets.

\subsection{Light armor target}

Figure 4 shows the numerical results of the ogive nose and flat-nose projectile impact on $12.7 \mathrm{~mm}$ thick RHA target at $30^{\circ}$ for impact velocity of $120 \mathrm{~m} / \mathrm{s}$. The ogive nose projectile has shown the ricochet behavior after impacting the RHA target; initially, it pushes the impacted area of the target inward. While after some time the nose and the front end of the projectile lifts and projectile tend to ricochet and slide along the surface of the target. However, the flat-nose projectile on impact initially pushes the target and after a short duration, the second shoulder of the projectile comes in contact with the impact region to reduce the ricochet behavior and projectile perforates the target. Therefore, flat- nose projectile is considered for further study in this paper to predict the targets perforation and projectile residual velocity estimations.

Figure 5 shows the flat-nose projectile impact on $12.7 \mathrm{~mm}$ thick RHA target for normal impact at a velocity of $120 \mathrm{~m} / \mathrm{s}$. In case of normal impact, the flat-nose projectile on impact creates a damage region and perforates the target with almost the size of its nose diameter and bounce back. At a maximum velocity of $300 \mathrm{~m} / \mathrm{s}$, both for normal and $30^{\circ}$ oblique impacts the flat-nose projectile penetrated through thick RHA targets easily with adequate residual velocity. Additionally, the minimum impact velocity of the flat-nose projectile was determined for oblique and normal impact through simulations to fully penetrate the RHA target. The simulation results predicted that $170 \mathrm{~m} / \mathrm{s}$ is the minimum impact velocity for the flat-nose projectile to defeat the light armor targets for both inclined and normal impact conditions. 


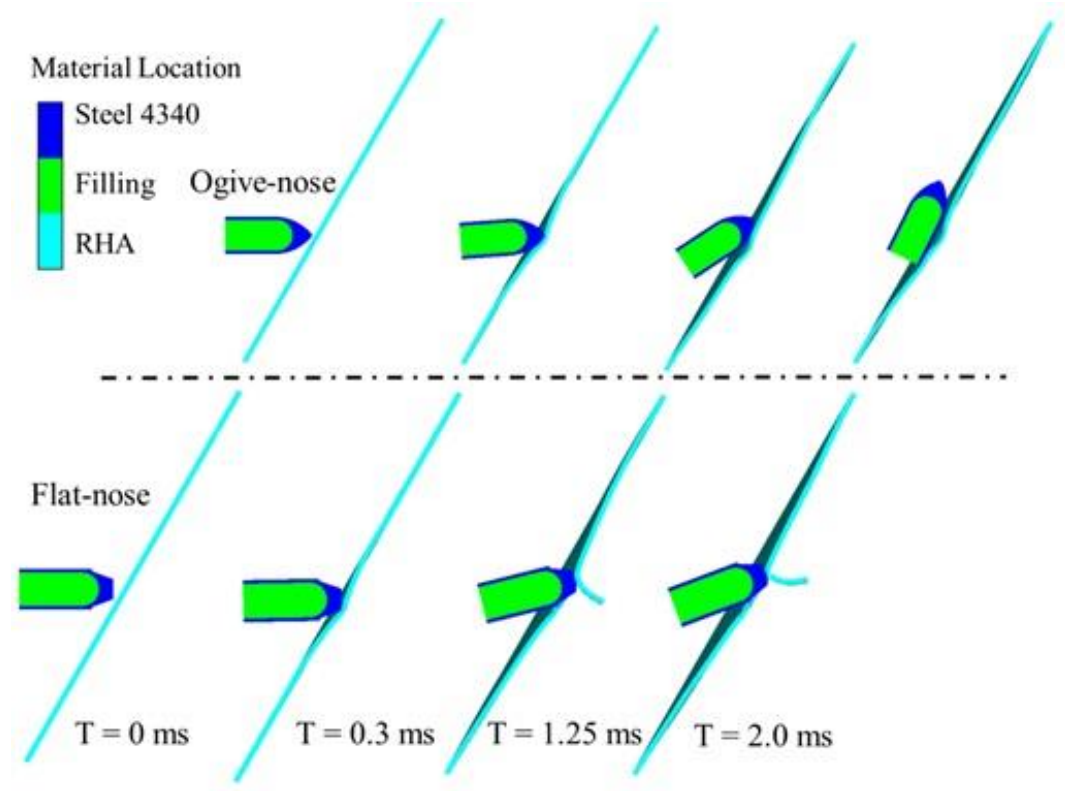

Figure 4: Oblique impact process of ogive and flat-nose projectile on RHA target at a minimum velocity

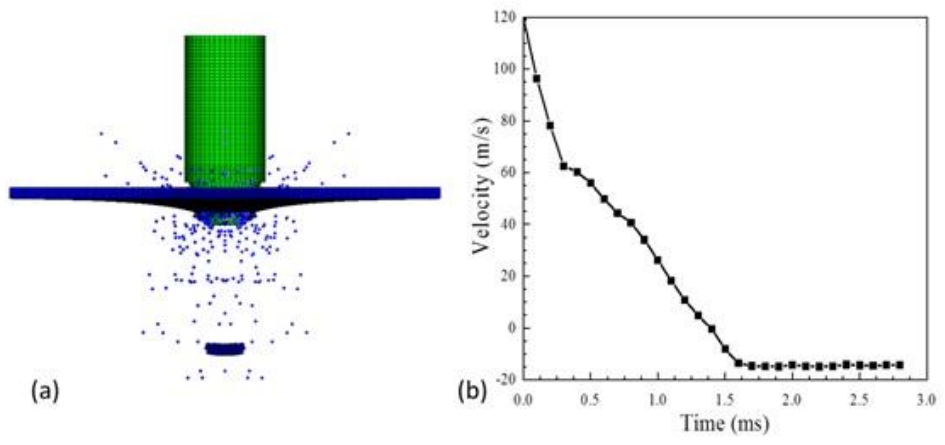

Figure 5: The flat-nose projectile perforation in RHA target (a) and velocity profile (b) for normal impact at $120 \mathrm{~m} / \mathrm{s}$

\subsection{Concrete target}

Simulations of the normal and oblique impact of unreinforced/plain concrete were performed at a minimum and maximum velocity for 8 inches thick targets.

At first, the simulation results are verified with the experiments for double and triple-brick wall targets for numerical scheme validation. The damage and deformation plots for normal impact incident at a minimum and maximum velocity are shown in figure 6 . At the impact velocity of $120 \mathrm{~m} / \mathrm{s}$ for the normal impact, the flat-nose projectile damaged the concrete target in the local area but projectile decelerated and embedded in the target as can be seen in figure $6(\mathrm{a})$. However, at the velocity of $300 \mathrm{~m} / \mathrm{s}$, the projectile was able to perforate the target and the projectile penetrated through the target with ample residual velocity. The projectile velocity and penetration depth profiles for normal impact cases at maximum and minimum velocity are shown in figure 7. 


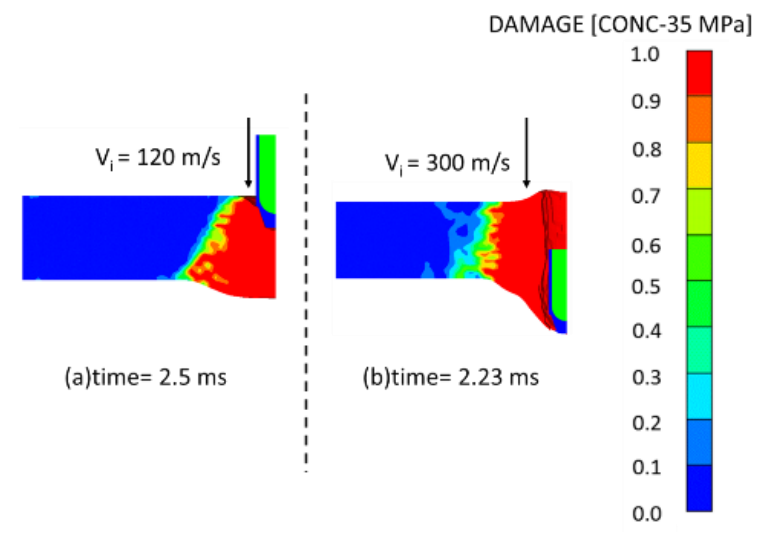

Figure 6: The damage and deformations for concrete target at normal impact (a) $V_{i}=120 \mathrm{~m} / \mathrm{s}$ (b) $V_{i}=300 \mathrm{~m} / \mathrm{s}$
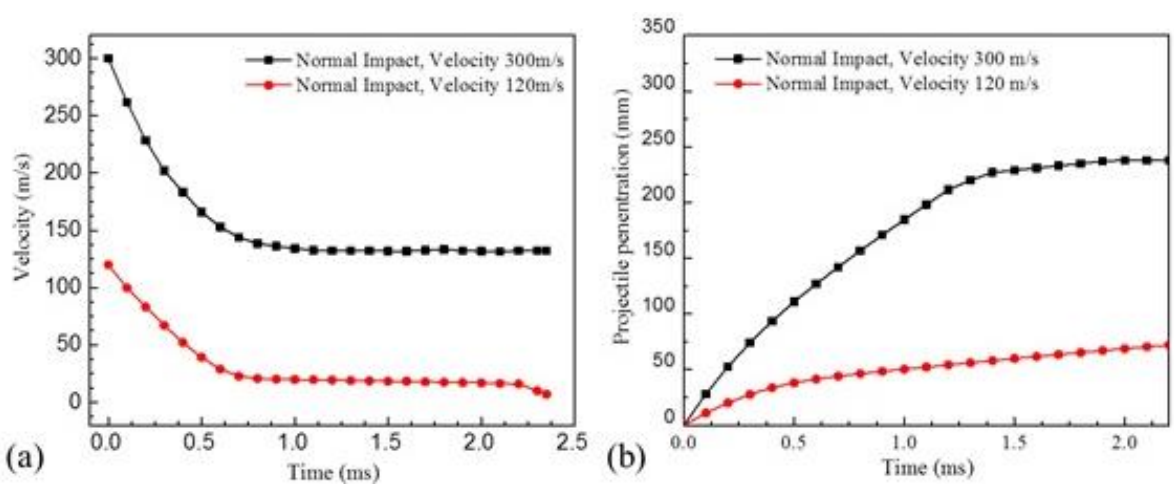

Figure 7: The projectile velocity profile (a) and penetration depth (b), in the concrete target at maximum and minimum velocity

The simulations are carried out at different velocities for normal impact and it was found that the minimum velocity of $250 \mathrm{~m} / \mathrm{s}$ is required for the flat-nose projectile to fully penetrate the $35 \mathrm{MPa}$ plain concrete target. The oblique impact simulations at maximum velocity are performed in the concrete target. Generally, oblique impact conditions pose more resistance in penetrating concrete targets to a projectile because of increased bending forces and high risk of projectile fracturing. However, in our simulations at a maximum velocity of $300 \mathrm{~m} / \mathrm{s}$ and with the casing thickness, projectile damages the plain concrete target and penetrate through with good residual velocity. The deformation and damage plot in the concrete target and projectile velocity profile for maximum impact velocity are shown in figure 8 .

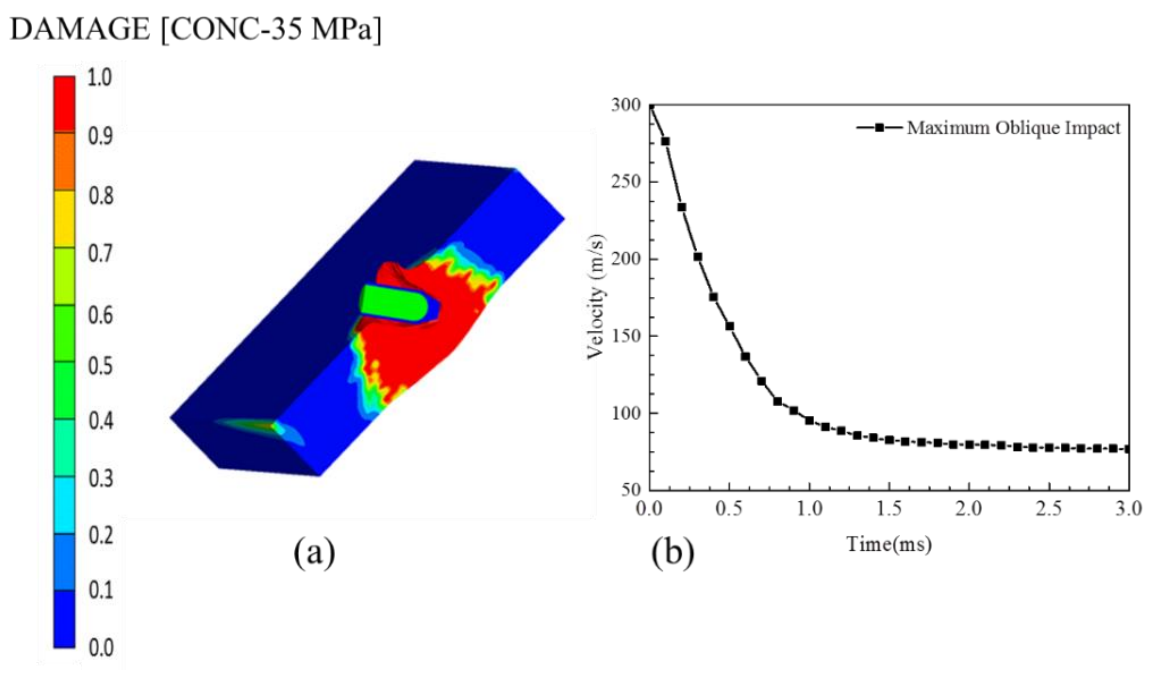

Figure 8: The damage plot in plain concrete at maximum velocity and obliquity (a), projectile velocity profile (b) 


\subsection{Brick wall targets}

Tests on double and triple-brick wall targets were conducted at a sub-sonic speed of $170 \mathrm{~m} / \mathrm{s}$ with flat-nose (FN) projectiles. Four projectiles with inert filling were prepared to have the same weight and center of gravity as of the actual one. A high-speed camera is used to calculate the projectile impact and residual velocity.

Figure 9 and 10 shows the penetration results of flat-nose projectile penetration on double and triple-layer brick wall targets for normal impact and the impact velocity was $170 \mathrm{~m} / \mathrm{s}$, respectively.

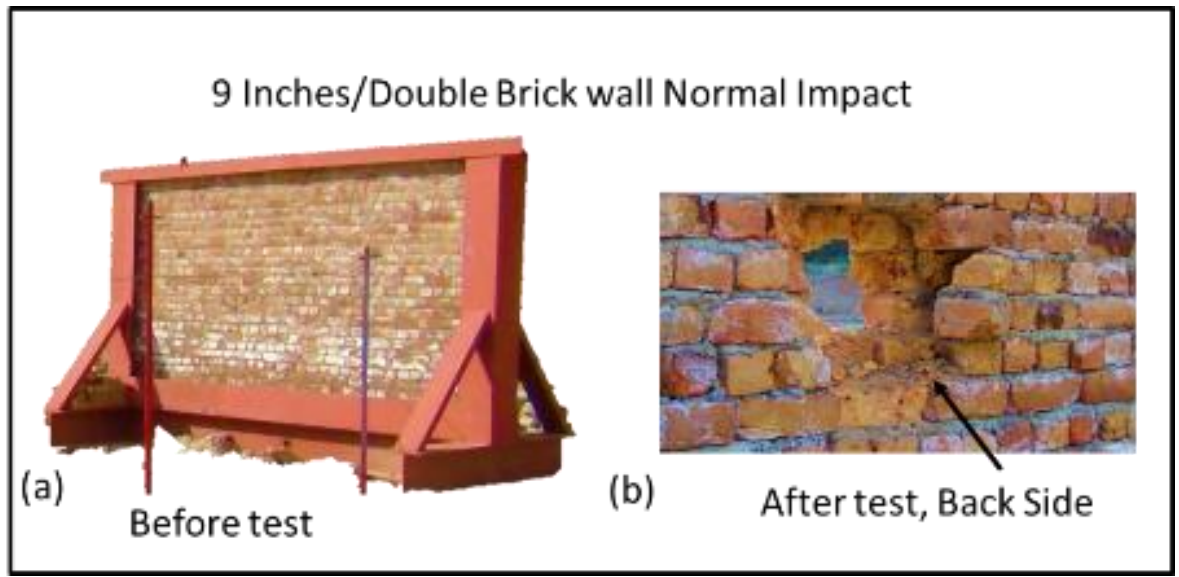

Figure 9: FN projectile normal impact on the double brick wall at a velocity of $170 \mathrm{~m} / \mathrm{s}$

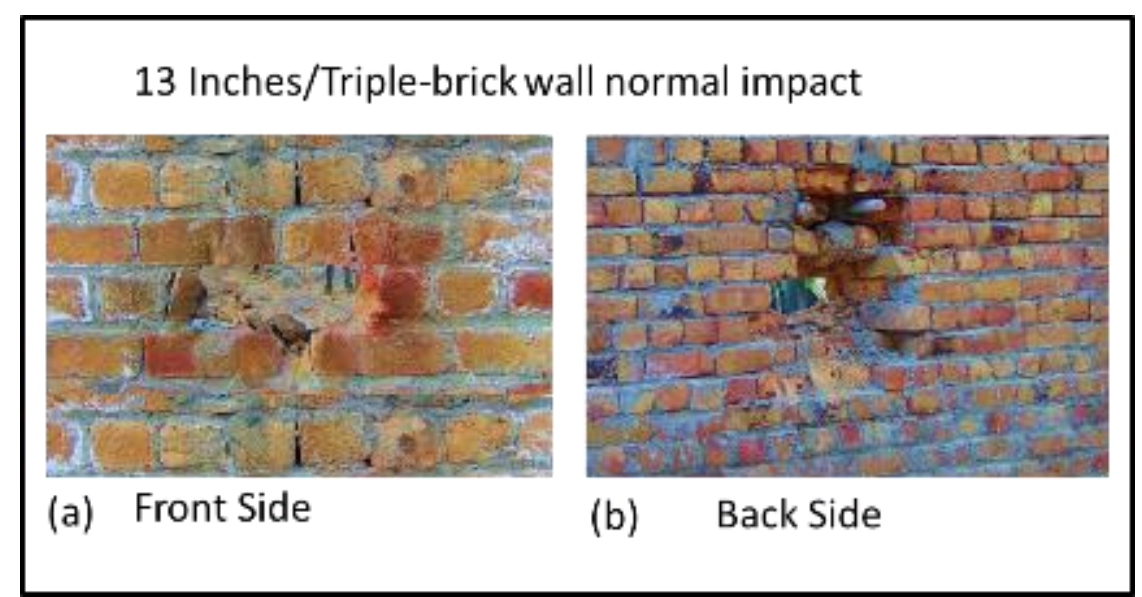

Figure 10: Penetration result in 13 inches triple-brick wall

The projectile damages both the target in the local area and fully penetrates through with less damage and spall. The recovered projectiles have experienced no deformation and targets were fully penetrated. Numerical simulations are conducted with velocity $170 \mathrm{~m} / \mathrm{s}$ to validate the calculated results for normal impact conditions. The results are shown in figure 11 for the triple brick-wall targets; the projectile only damages the brick-walls in the local region of an impact as observed in field tests. The calculated velocity history plots of the projectile normal impact on double and triple brick-wall are also shown in figure 12. 


\section{AUTOOYN-30 V 4.0 from ANSYS}

Material Location

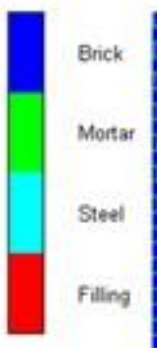

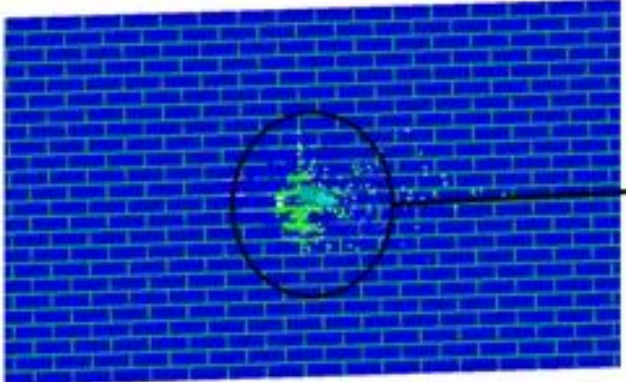

(a) Impact on 13 Inches Wall

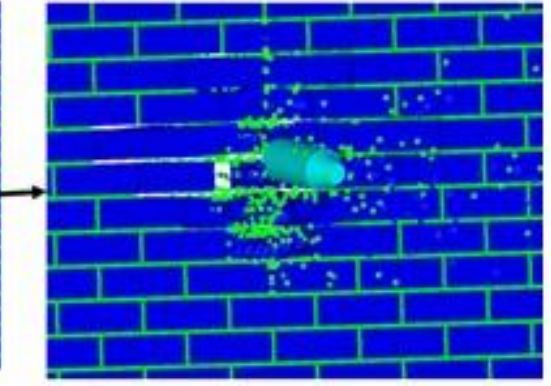

(b) Impact Area

Figure 11: Numerical results for 13 inches brick-wall for normal impact at an impact velocity of $170 \mathrm{~m} / \mathrm{s}$

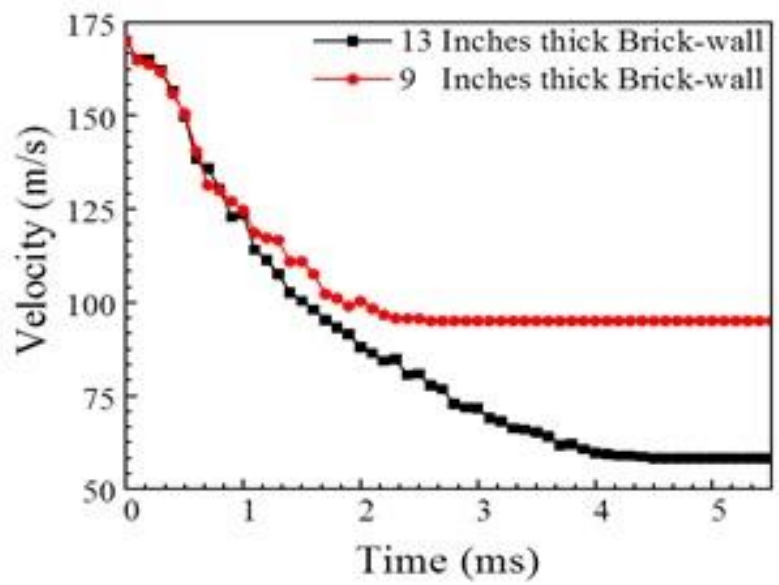

Figure 12: Velocity profile for penetration simulation on double and triple brick-wall for normal impact at $170 \mathrm{~m} / \mathrm{s}$

The residual velocity of the projectile was estimated through high-speed frames tracking although it was difficult to locate the projectile due to debris clouds after penetration. The high-speed image of triple brick-wall test and recovered projectile are shown in figure 13.

(a)

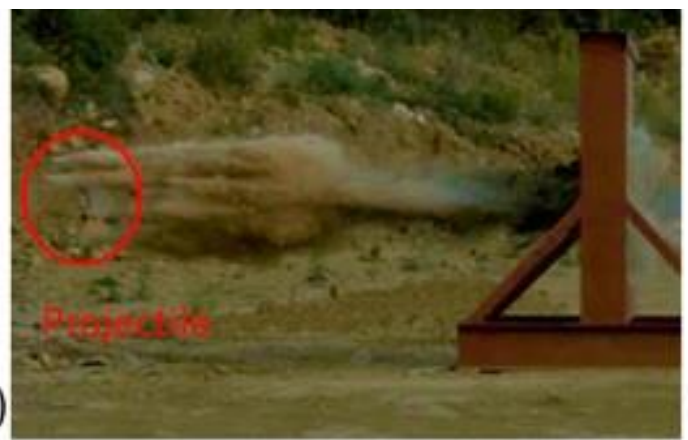

(b)

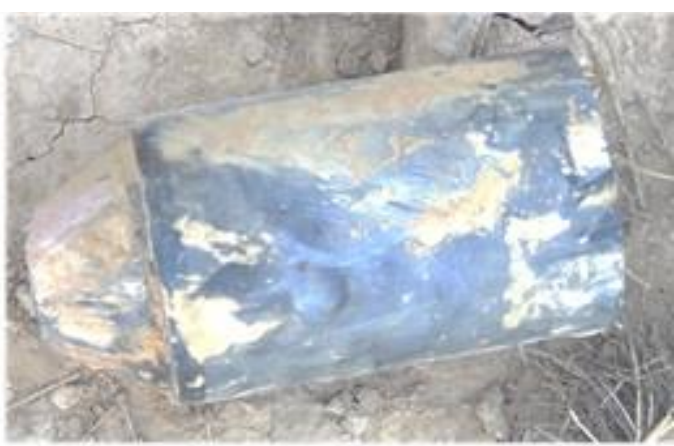

Figure 13: (a) The high-speed image of 13-inch brick-wall penetration test (b) recovered projectile

Numerical simulations are further completed for minimum and maximum velocity at normal and oblique impact conditions. The numerical results suggested that both the double and triple-brick wall targets were fully perforated by a projectile at a minimum and maximum velocity for normal and oblique impact scenarios. Figure 14 shows the residual velocity plot of the projectile for oblique and normal impact cases for double and triple brick-wall targets. 
The table-6 lists the residual velocity results obtained from simulation and experimentation for normal impacts. In present work calculated and experimental results have a good agreement, which supports the heterogeneous modeling technique of brick-wall, constitutive model, and parameters proposed by [7].

Table 6: Comparison of projectile residual velocity $(\mathrm{m} / \mathrm{s})$

\begin{tabular}{ccc}
\hline & Simulation & Experiment \\
\hline Double brick-wall & 95.6 & 92.5 \\
\hline Triple brick-wall & 60 & 57.5 \\
\hline
\end{tabular}

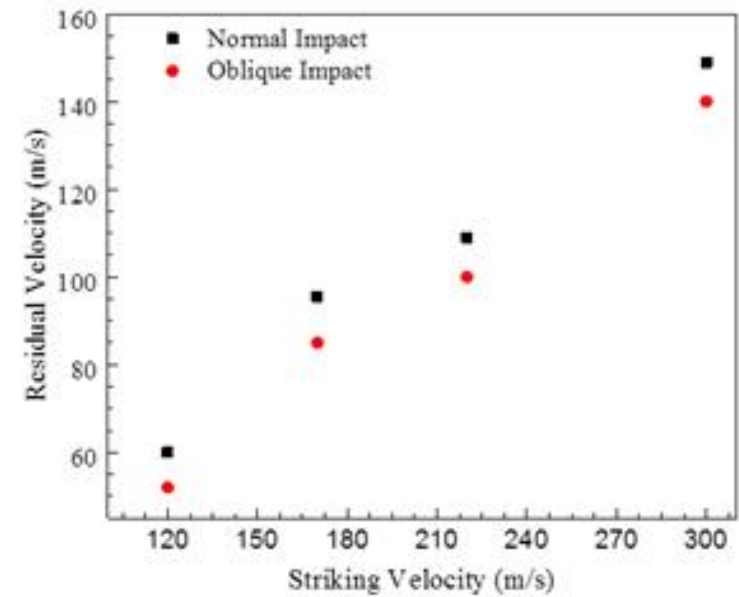

(a)

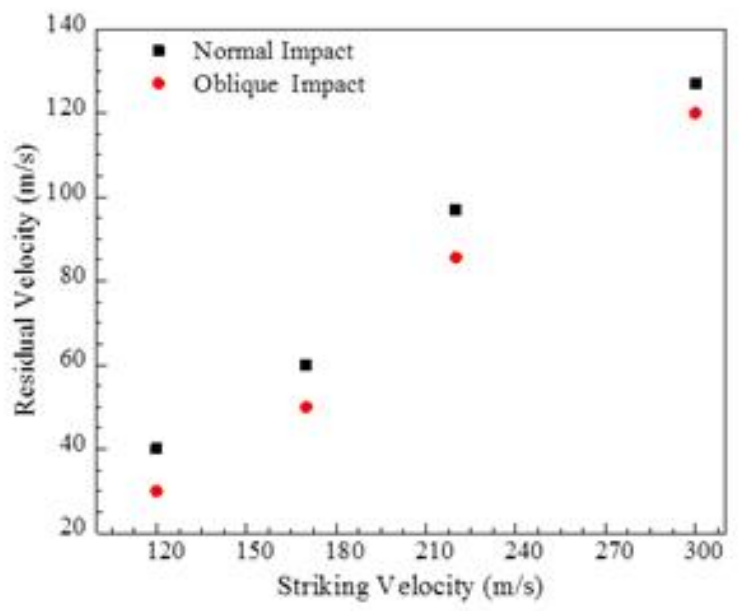

(b)

Figure 14: Residual velocity plots for projectile at various impacting velocities, (a) double, (b) triple brick-wall targets

The summary of all the calculated results for penetration performance of projectile in aforementioned targets is presented in table-7.

Table 7: Summary of simulation results

\begin{tabular}{|c|c|c|c|c|c|}
\hline Target type & $\begin{array}{c}\text { Projectile } \\
\text { shape }\end{array}$ & $\begin{array}{c}\text { Impact velocity } \\
(\mathrm{m} / \mathrm{s})\end{array}$ & Angle & Target perforation & $\begin{array}{c}\text { Residual velocity } \\
(\mathrm{m} / \mathrm{s})\end{array}$ \\
\hline \multicolumn{6}{|l|}{ Light armor } \\
\hline & Ogive nose & 120 & $30^{\circ}$ & No, & $\begin{array}{c}\text { Projectile Rico- } \\
\text { chet }\end{array}$ \\
\hline & FN & 120 & $0^{\circ}$ & $\begin{array}{c}\text { Yes, projectile re- } \\
\text { bounded }\end{array}$ & -- \\
\hline & $\mathrm{FN}$ & 120 & $30^{\circ}$ & Yes & 0 \\
\hline & $\mathrm{FN}$ & 170 & $0^{\circ}$ & Yes & 40 \\
\hline & FN & 170 & $30^{\circ}$ & yes & 20.34 \\
\hline & FN & 300 & $0^{\circ}$ & Yes & 220 \\
\hline & $\mathrm{FN}$ & 300 & $30^{\circ}$ & Yes & 211.5 \\
\hline \multicolumn{6}{|l|}{ Concrete } \\
\hline & FN & 120 & $0^{\circ}$ & $\begin{array}{c}\text { No, Projectile } \\
\text { embedded in the target }\end{array}$ & 0 \\
\hline & $\mathrm{FN}$ & 220 & $0^{\circ}$ & Yes & 37.88 \\
\hline
\end{tabular}




\begin{tabular}{|c|c|c|c|c|c|}
\hline & $\mathrm{FN}$ & 220 & $30^{\circ}$ & $\begin{array}{c}\text { No, Projectile } \\
\text { embedded in the target }\end{array}$ & 0 \\
\hline & $\mathrm{FN}$ & 250 & $0^{\circ}$ & Yes & 58.64 \\
\hline & $\mathrm{FN}$ & 250 & $30^{\circ}$ & Yes & 34.5 \\
\hline & FN & 300 & $0^{\circ}$ & Yes & 132.35 \\
\hline & $\mathrm{FN}$ & 300 & $30^{\circ}$ & Yes & 76.85 \\
\hline \multicolumn{6}{|l|}{ Brick-wall } \\
\hline \multirow[t]{8}{*}{9 inches } & $\mathrm{FN}$ & 120 & $0^{\circ}$ & Yes & 60 \\
\hline & $\mathrm{FN}$ & 120 & $30^{\circ}$ & Yes & 52 \\
\hline & $\mathrm{FN}$ & 170 & $0^{\circ}$ & Yes & 95.6 \\
\hline & $\mathrm{FN}$ & 170 & $30^{\circ}$ & Yes & 85 \\
\hline & $\mathrm{FN}$ & 220 & $0^{\circ}$ & Yes & 109 \\
\hline & FN & 220 & $30^{\circ}$ & Yes & 100 \\
\hline & $\mathrm{FN}$ & 300 & $0^{\circ}$ & Yes & 149 \\
\hline & $\mathrm{FN}$ & 300 & $30^{\circ}$ & Yes & 140 \\
\hline \multirow[t]{8}{*}{13 inches } & $\mathrm{FN}$ & 120 & $0^{\circ}$ & Yes & 40 \\
\hline & $\mathrm{FN}$ & 120 & $30^{\circ}$ & Yes & 30 \\
\hline & $\mathrm{FN}$ & 170 & $0^{\circ}$ & Yes & 60 \\
\hline & $\mathrm{FN}$ & 170 & $30^{\circ}$ & Yes & 50 \\
\hline & $\mathrm{FN}$ & 220 & $0^{\circ}$ & Yes & 97 \\
\hline & FN & 220 & $30^{\circ}$ & Yes & 85.6 \\
\hline & $\mathrm{FN}$ & 300 & $0^{\circ}$ & Yes & 127 \\
\hline & FN & 300 & $30^{\circ}$ & Yes & 120 \\
\hline
\end{tabular}

\section{CONCLUSIONS}

In this paper, projectiles impact on three different targets (RHA, concrete, and brick-wall) for various velocities at normal and oblique impact is analyzed. The dynamic simulations using non-linear codes ANSYS/Autodyn are capable of predicting the perforation and penetration performance of projectiles to various targets and can save the experimentation cost. The results obtained would be beneficial for the designers and operators to get the desired performance against domestic and light armor targets with confidence. The simulations and test results will also be beneficial for fuze designers to recognize the targets like (RHA, concrete, and brick-wall) and set the appropriate delay time in weapons system to achieve the optimal performance.The following outcomes are drawn from present work:

1) The projectile nose shape has significant importance for low velocity and oblique impact conditions on RHA targets and it is suggested to develop a flat-nose (FN) instead of an ogive-nose projectile. Moreover, the minimum velocity of $170 \mathrm{~m} / \mathrm{s}$ is required for defeating light armor targets both for normal and maximum obliquity.

2) The 8 inches thick plain concrete targets of compressive strength $35 \mathrm{MPa}$ are difficult to fully penetrate with sufficient residual velocities. However, numerical simulations results suggested that the designed flat-nose (FN) penetrator with a striking velocity of higher than $250 \mathrm{~m} / \mathrm{s}$ is capable to completely damage, perforate and penetrate the concrete targets.

3) The dynamic continuum damage material model has been used to model the brick and mortar, simulation results using this model showed good agreement with the experiments in terms of damage area and residual velocity. The FN projectile calculated results suggested that it is able to penetrate through the double and triple brick-wall at minimum velocity and at maximum obliquity.

\section{ACKNOWLEDGEMENT}

This work has been supported by NSFC and PSF (5171101743). The authors would like to thank Dr. Sajid Raza Ch, Mr. Mirza Amjad Baig, Dr. Jawad Khawer and Mr. Muhammad Amin for their valuable guidance, technical and administrative support during the course of this research, without which this work would not have been possible. 


\section{BIBLIOGRAPHY}

[1] FAIRLIE, G., LIVINGSTONE, I. H., "Analysis of fragment throw distances from high explosive detonations in masonry structures", 9th International Symposium on Interaction of the Effects of Munitions with Structures, Berlin, Germany, 1999.

[2] BIRNBAUM, N. K., FAIRLIE, G. E., XIANGYANG, Q., "Coupled Fluid-Structure Analysis of High Explosive Detonations in Masonry Structures", In: 29th DOD Explosives Safety Seminar, New Orleans, USA, 2000.

[3] QUAN, X., BIRNBAUM, N. K., COWLER, M. S., et al., "Numerical simulation of structural deformation under shock and impact loads using a coupled multi-solver approach", In: Proceedings of 5th AsiaPacific Conference on Shock and Impact Loads on Structures, pp. 12-14. 2003.

[4] PAVlOVIC, A., FRAGASSA, C., DISIC, A. "Comparative numerical and experimental study of projectile impact on reinforced concrete”, Composites Part B: Engineering, v.108, pp.122-130, 2017.

[5] FISCHER, K., RIEDEL, W., ZIEHM, J., "Full-scale validation of a blast-proof masonry wall system and assessment of coupling effects using a TDOF model", 14th International Symposium on Interaction of the Effects of Munitions with Structures-ISIEMS, 2011.

[6] SCHWER, L. E. "Simple input concrete constitutive models: An illustration of brick wall \& concrete cylinder perforation”, In: 10th International LS-DYNA Users Conference, pp. 20-39, 2008.

[7] ZHOU, X. Q., HAO, H., DEEK, A. J., "Numerical modeling of response and damage of masonry walls to blast loading”, Transactions of Tianjin University, v. 12, pp. 132-137, 2006.

[8] AKERS, S., EHRGOTT, J., RICKMAN, D., "Breaching of Triple-Brick Walls: Numerical Simulations", In:DoD High Performance Computing Modernization Program Users Group Conference, pp. 7-11. IEEE, 2007.

[9] THAM, C. Y. "Reinforced concrete perforation and penetration simulation using AUTODYN-3D", Finite Elements in Analysis and Design, v. 41, n. 14, pp. 1401-1410, 2005.

[10] ZAKIR, S. M., LI, Y.L., SUO, T. "Numerical prediction of projectile residual velocity after penetration of reinforced concrete with different reinforcing bar arrangements", Materials Research Innovations, v. 15, n. sup 1, pp. s191-s194, 2011.

[11] GRUJICIC, M., BELL, W.C., "Smart-fuze Design and Development Based on Computational Analysis of Warhead/Urban-target Interactions", Researches and Applications in Mechanical Engineering, v. 2, n. 1, pp. 1-10, 2013.

[12] LIPS, H., RITTEL, R., "Development of a subsonic anti-structure-penetrator", In: 26th International symposium on ballistics, Miami, Florida, USA, September 12-16, 2011.

[13] LI, Z., CHEN, L., FANG, Q., et al., "Experimental and numerical study of unreinforced clay brick masonry walls subjected to vented gas explosions", International Journal of Impact Engineering, v. 104, pp. 107-126, 2017.

[14] JOHNSON, G. R., WILLIAM H. COOK. "A constitutive model and data for metals subjected to large strains, high strain rates and high temperatures", In: Proceedings of the 7th International Symposium on Ballistics, v. 21, no. 1, pp. 541-547, 1983.

[15] ANSYS Inc. AUTODYN user manual version 13; 2010.

[16] RIEDEL, W., "10 Years RHT: A Review of Concrete Modelling and Hydrocode Applications", In: Predictive Modeling of Dynamic Processes, pp. 143-165. Springer US, 2009.

[17] HERRMANN, W. "Constitutive equation for the dynamic compaction of ductile porous materials", Journal of applied physics, v. 40, n. 3, pp. 2490-9, 1969.

[18] MA, G., HAO, H., LU, Y. "Homogenization of masonry using numerical simulation", Journal of engineering mechanics, v. 127, pp. 421-431, 2001.

[19] MORELAND, C., HAO, H., WU, C., "Response of retrofitted masonry walls to blast loading", In: Proceedings of the 6th international conference on shock and impact loading on structures, Perth, Australia, 7-9, December 2005.

[20] WEI, X., STEWART, M. G., "Model validation and parametric study on the blast response of unreinforced brick masonry walls", International journal of impact engineering, v. 37, n. 11, pp. 1150-1159, 2010.

[21] MEYER, C. S., "Development of brick and mortar material parameters for numerical simulations using the Holmquist-Johnson-Cook constitutive model for concrete", In: 26th International symposium on ballis- 
tics, Miami, Florida, USA, September 12-16, 2011.

[22] HAO, H., TARASOV B. G., "Experimental study of dynamic material properties of clay brick and mortar at different strain rates", Australian Journal of Structural Engineering, v. 8, n. 2, pp. 117-132, 2008.

[23] WEI, X., HAO, H., "Numerical derivation of homogenized dynamic masonry material properties with strain rate effects", International Journal of Impact Engineering, v. 36, n. 3, pp. 522-536, 2009. 